\title{
ANALISIS PENGGUNAAN PERANGKAT PEMBELAJARAN GURU BIOLOGI DI SMA NEGERI 1 KOTA LANGSA PADA MASA PANDEMI COVID-19
}

\author{
Luther Ananda Sitompul ${ }^{1}$, Sofiyan ${ }^{2}$, Nursamsu $^{3}$ \\ Program Studi Pendidikan Biologi, Fakultas Keguruan dan Ilmu Pendidikan, \\ Universitas Samudra,
}

Email : luthersitompul23@gmail.com

\begin{abstract}
ABSTRAK
Penelitian ini bertujuan untuk mengetahui perangkat pembelajaran yang digunakan oleh guru biologi di SMA Negeri 1 Kota Langsa sesuai ketentuan pembelajaran pada masa pandemi Covid-19. Penelitian ini menggunakan metode penelitian kualitatif dengan pendekatan deskriptif. Teknik pengumpulan data pada penelitian ini adalah observasi, wawancara dan dokumentasi. Analisis data dalam penelitian ini menggunakan metode Miles dan Huberman dengan prosedur reduksi data (data reduction), penyajian data (data display) dan verifikasi data (data verification). Hasil penelitian menunjukkan penggunaan perangkat pembelajaran berupa RPP sebanyak $87,75 \%$ dengan kategori penilaian sangat baik, LKPD sebanyak $82,85 \%$ dengan kategori penilaian sangat baik, penggunaan media pembelajaran sebanyak 78,56\% dengan kategori penilaian baik dan tes hasil belajar sebanyak $80,95 \%$ dengan kategori penilaian sangat baik. Disimpulkan bahwa guru biologi di SMA Negeri 1 Langsa memiliki perangkat pembelajaan biologi yang sangat lengkap. Sebagian guru menggunakan RPP daring dan selebihnya masih menggunakan RPP luring. Seluruh guru biologi menggunakan media pembelajaran untuk belajar namun seorang guru biologi tidak melakukan praktikum di masa pandemi. Disarankan agar guru biologi menggunakan perangkat pembelajaran sesuai ketentuan pada masa pandemi Covid-19 dengan maksimal dan sekolah memfasilitasi dalam penyusunan perangkat pembelajaran tersebut.
\end{abstract}

Kata Kunci: Perangkat Pembelajaran, Guru, RPP, Media Pembelajaran, Daring

\section{ABSTRACT}

This study aims to determine the learning tools used by biology teachers at SMA Negeri 1 Langsa City according to the learning provisions during the Covid-19 pandemic. This study uses a qualitative research method with a descriptive approach. Data collection techniques in this study were observation, interviews and documentation. Data analysis in this study uses the Miles and Huberman method with data reduction procedures (data reduction), data display (data display) and data verification (data verification). The results showed the use of learning tools in the form of lesson plans as much as $87.75 \%$ with a very good assessment category, LKPD as much as $82.85 \%$ with a very good assessment category, the use of learning media as much as $78.56 \%$ with a good assessment category and $80.95 \%$ learning outcomes tests. with a very good rating category. It was concluded that the biology teacher at SMA Negeri 1 Langsa had a very complete set of biology learning tools. Some teachers use online lesson plans and the rest still use offline lesson plans. All biology teachers use learning media to learn, but a biology teacher does not do practicum during the pandemic. It is recommended that biology teachers use learning tools according to the provisions during the Covid-19 pandemic to the maximum and schools facilitate the preparation of these learning devices.

Keywords: Learning tools, Teacher, Lesson plan, Learning Media, Online learning 


\section{PENDAHULUAN}

Pendidikan menjadi elemen penting dalam memajukan bangsa yang dibuktikan dengan perkembangan dan kemajuan segala bidang yang ditentukan oleh keberhasilan pendidikan (Sulistyo, 2013). Perkembangan pendidikan sekarang terhambat oleh pandemi Covid-19 yang menerjang seluruh dunia dan merubah seluruh aspek Pendidikan salah satunya aktivitas belajar. Hal ini membuat pemerintah melalui Kementerian Pendidikan dan Kebudayaan pada Surat Edaran Kemendikbud Nomor 15 Tahun 2020 tentang Pedoman Penyelenggaraan Belajar Dari Rumah Dalam Masa Darurat Penyebaran Covid-19. Aturan tersebut juga merubah tatanan penyusunan dan penggunaan perangkat pembelajaran. Perangkat pembelajaran adalah seperangkat alat, petunjuk atau pedoman pegangan guru yang digunakan untuk melaksanakan proses yang memungkinkan pendidik dan peserta didik untuk melakukan kegiatan belajar mengajar (Nugroho, 2014).

Perangkat yang digunakan dalam proses kegiatan belajar mengajar tersebut meliputi silabus, rencana pelaksanaan pembelajaran (RPP), lembar kerja peserta didik (LKPD), buku atau materi ajar, media pembelajaran dan tes hasil belajar
(THB). Guru sebagai garda terdepan pendidikan harus menyusun perangkat pembelajaran sesuai dengan aturan, inovatif dan relevan dengan kondisi siswa dan materi yang akan disampaikan. Guru juga harus berupaya membangun proses pembelajaran yang menarik dalam kegiatan pembelajaran daring pada masa pandemi (Andini, 2020).

Hasil observasi di sekolah menunjukkan bahwa masih ada penggunaan RPP luring pada pembelajaran sehingga perlu dilakukan penelitian lebih lanjut dan mendalam apakah selama masa pandemi Covid-19 setiap guru biologi menggunakan perangkat yang lama atau telah merubah kembali sesuai dengan anjuran Kementerian Pendidikan dan Kebudayaan Republik Indonesia tentang Pembelajaran Pada Masa Pandemi.

$$
\text { Berdasarkan hasil pemaparan }
$$
tersebut peneliti tertarik untuk melakukan analisis penggunaan perangkat pembelajaran guru biologi di SMA Negeri 1 Kota Langsa pada masa pandemi Covid19.

\section{METODE PENELITIAN}

\section{a. Waktu dan Tempat Penelitian}

Penelitian ini dilaksanakan pada tanggal 26 Juli 2021 sampai 2 Agustus 2021. Penelitian ini dilakukan di SMA Negeri 1 
Langsa, Kecamatan Langsa Baro, Kota Langsa Provinsi Aceh.

\section{b. Sampel Penelitian}

Sesuai dengan wilayah generalisasinya, peneliti menggunakan populasi yakni seluruh guru mata pelajaran Biologi di SMA Negeri 1 Langsa dan terdata dalam sistem administratif sekolah. Sampel yang digunakan dalam penelitian ini adalah seluruh anggota populasi karena tidak dapat dilakukan generalisasi terhadap populasi. Untuk itu, sampel yang digunakan sebanyak 7 orang.

Penelitian ini termasuk kedalam penelitian kualitatif dengan pendekatan deskriptif. Pendekatan ini digunakan untuk mendapatkan data mengenai penggunaan perangkat pembelajaran guru Biologi di SMA Negeri 1 Langsa.

\section{c. Teknik Pengumpulan Data}

Teknik pengumpulan data pada penelitian ini menggunakan cara observasi, wawancara dan dokumentasi. Observasi dilakukan dengan pedoman observasi. Wawancara dilakukan dengan instrumen berupa pedoman wawancara semiterstruktur. Pelaksanaan terakhir adalah dokumentasi. Dokumentasi dilakukan dengan dokumentasi resmi seperti sumber data primer dan sumber data sekunder. d. Analisis Data

Analisis data kualitatif dalam penelitian ini dilakukan dengan metode Miles dan Huberman. Prosedur analisis data sesuai metode ini yaitu reduksi data (data reduction), penyajian data (data display) yang diorganisasikan dalam bentuk persentase dan ditelaah berdasarkan kategori tolak ukur persentase. Terakhir adalah verifikasi data (data verification).

\section{HASIL DAN PEMBAHASAN}

\section{Hasil Penelitian}

\section{Profil Guru Biologi di SMA Negeri 1}

\section{Langsa}

Hasil penelitian yang telah dilakukan bahwa profil guru Biologi di SMA Negeri 1 Langsa dijelaskan pada tabel 1. berikut.

Tabel 1. Kutipan Jumlah Guru Biologi di SMA Negeri Langsa Tahun 2021

\begin{tabular}{|c|l|}
\hline NO & \multicolumn{1}{|c|}{ NAMA } \\
\hline 1 & Drs. Syukri \\
\hline 2 & Hasnawati, M.Pd \\
\hline 3 & Supriadi, S.Pd \\
\hline 4 & Yusniati, S.Pd \\
\hline 5 & Eka Khairisma, S.Pd \\
\hline 6 & Idham Khalid, S.Pd \\
\hline 7 & M. Mahdi, S.Pd \\
\hline
\end{tabular}

\section{Penggunaan Perangkat Pembelajaran}

Guru Biologi di SMA Negeri 1 Langsa 
Pelaksanaan implementasi perangkat pembelajaran yang dibuat oleh guru biologi di SMA Negeri 1 Langsa disajikan sebagai berikut:

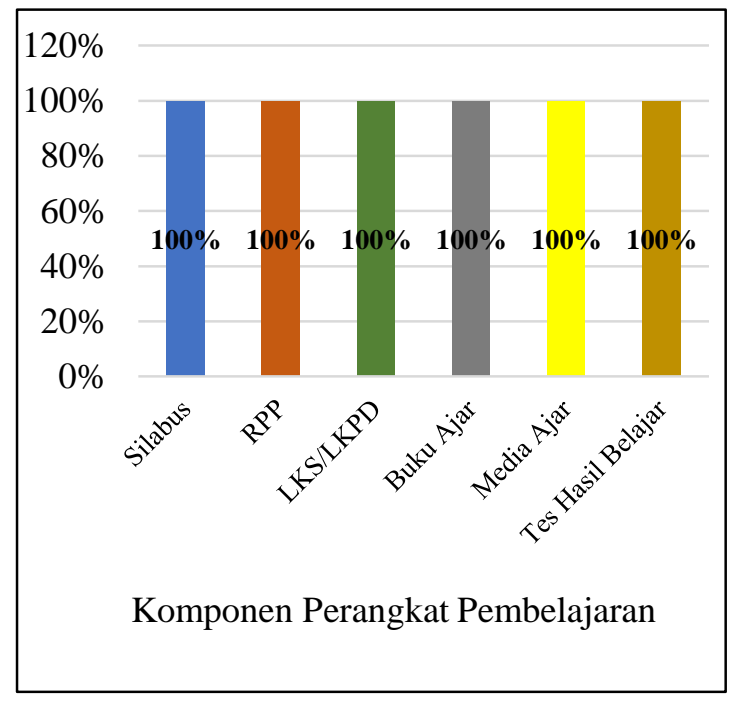

Gambar 1. Grafik Persentase Kelengkapan Komponen perangkat pembelajaran Guru Biologi di SMA Negeri 1 Langsa

Hasil rekapan penilaian kelengkapan komponen perangkat pembelajaran guru Biologi di SMA Negeri 1 Langsa sesuai dengan Permendikbud Nomor 22 Tahun 2016 teungkap bahwa kelengkapan komponen perangkat pembelajaran dari 7 guru sudah lengkap sesuai dengan peraturan Menteri Pendidikan tentang Standar Proses Pendidikan Dasar Menengah. Perangkat pembelajaran juga menggunakan bentuk kurikulum 2013. Berdasarkan dari persentase tingkat kelengkapan, dapat dilihat bahwa $100 \%$ guru biologi di SMA Negeri 1 Langsa menggunakan silabus,
RPP, LKPD, materi ajar, media ajar dan penilaian hasil belajar.

Gambar 2 dibawah ini menunjukan rata-rata penggunaan setiap perangkat pembelajaran guru biologi di SMA Negeri 1 Langsa berupa RPP, LKPD, Materi ajar, Media Ajar dan Tes Hasil Belajar. Hasil rekapitulasi menunjukkan rerata bahwa pengggunaan RPP sebanyak 87,75\% dengan kategori penilaian sangat baik, LKPD sebanyak $82,85 \%$ dengan kategori penilaian sangat baik, media pembelajaran sebanyak $71,42 \%$ dengan kategori penilaian baik, buku atau materi ajar sebanyak 78,56\% dengan kategori penilaian baik dan tes hasil belajar sebanyak $80,95 \%$ dengan kategori penilaian sangat baik.

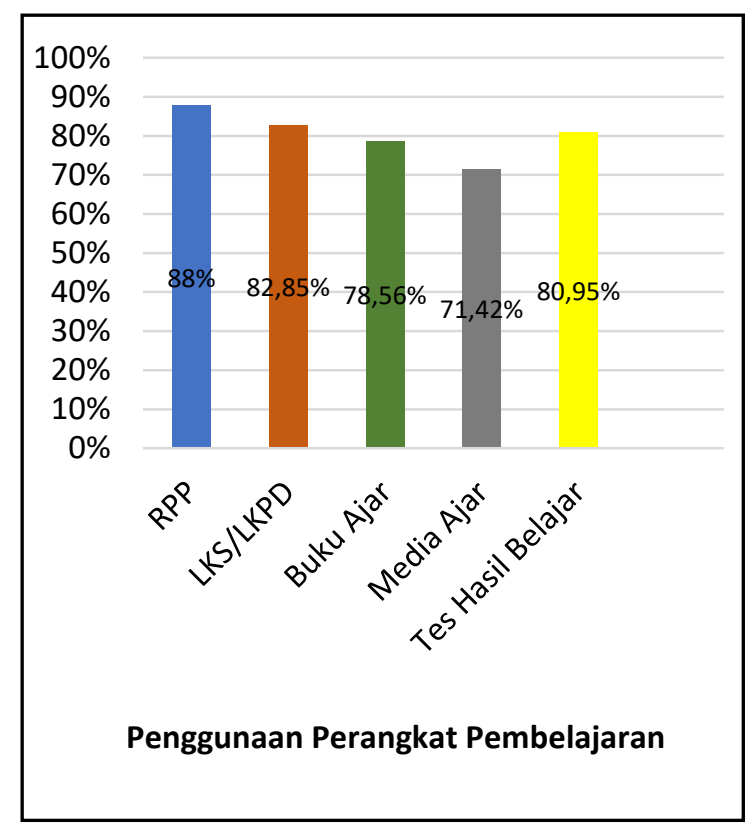

Gambar 2. Rekapitulasi Rerata Penggunaan Perangkat Pembelajaran Guru Biologi di SMA Negeri 1 Langsa 


\section{Pembahasan}

Perangkat pembelajaran adalah alat bantu atau perlengkapan untuk melaksanakan proses yang memungkinkan guru dan siswa melakukan kegiatan pembelajaran dan penyusunan perangkat pembelajaran merupakan bagian dari perencanaan pembelajaran sehingga secara tidak langsung sekolah dalam waktu singkat harus memikirkan strategi pembelajaran jarak jauh maupun strategi pertemuan fisik singkat sesuai dengan kompetensi guru, siswa, orangtua maupun dari sarana yang dimiliki (Nurwinda, 2020). Penelitian Nursamsu (2016) yang menyatakan bahwa dalam proses pelaksanaan pembelajaran tidak lepas dari bagaimana guru mendesain pembelajaran. Hal ini berarti guru wajib mendesain pembelajaran yang dibuktikan dengan adanya perangkat pembelajaran untuk menunjang kegiatan tersebut.

Berdasarkan hasil observasi dan dokumentasi dengan guru biologi pada mengenai kelengkapan komponen perangkat pembelajaran, terungkap bahwa seluruh guru biologi memiliki komponen perangkat pembelajarn yang lengkap mulai dari silabus, RPP, LKPD, Buku Siswa, Media Ajar dan Penilaian Hasil Belajar. Bentuk-bentuk perangkat pembelajaran ini sudah sesuai dengan aturan pemerintah pada Permendikbud No. 22 Tahun 2016 yang mengatur tentang bentuk-bentuk perangkat pembelajaran sesuai kurikulum 2013. 100\% guru menggunakan perangkat pembelajaran tersebut untuk melakukan proses belajar mengajar. Dari hasil persentase ini dapat dikatakan guru memiliki perangkat pembelajaran yang lengkap. Berdasarkan hasil wawancara dengan seluruh guru terungkap fakta bahwa sekolah melakukan pelatihan dan sosialisasi kepada guru termasuk guru biologi tentang kelengkapan perangkat pembelajaran terkait kurikulum 2013. Fakta yang muncul adalah sosialisasi tersebut dilaksanakan secara merata dan diikuti seluruh guru tanpa berhalangan. Sosialisasi tersebut dilakukan pada tingkat regional.

RPP memiliki komponen utama antara lain memuat tujuan pembelajaran khusus, materi pelajaran, kegiatan pembelajaran dan alat penilaian proses. RPP juga sekurang-kurangnya memuat indentitas, tujuan, materi, metode, kegiatan belajar, sumber media dan penilaian. RPP juga dikembangkan dari silabus untuk mengarahkan kegiatan pembelajaran peserta didik dalam upaya mencapai Kompetensi Dasar (KD) (Suciati, 2016). seluruh guru sudah menyusun RPP dengan benar. RPP memiliki komponen lengkap seperti identitas sekolah dengan penulisan yang benar, identitas mata pelajaran yang tercantum, mencantumkan kelas/ semester, 
mencantumkan materi pokok, mencantumkan alokasi waktu pembelajaran, mencantumkan tujuan pembelajaran, mencantumkan materi pembelajaran, mencantumkan Kompetensi Dasar dan Indikator Pencapaian Kompetensi pada satu materi tertentu, mencantumkan metode pembelajaran yang digunakan, mencantumkan media pembelajaran yang dipakai, mencamtumkan langkah-langkah pembelajaran dan membuat penilaian hasil belajar.

Berdasarkan observasi lapangan ternyata terungkap hanya 3 dari 7 $(42,85 \%)$ guru yang menyusun RPP berjenis daring. RPP daring pada hakikatnya sama dengan RPP kurikulum 2013 pada umumnya namun terdapat sedikit perubahan tertentu. Hal ini mengacu kepada arahan Surat Edaran Kementerian Pendidikan No. 15 Tahun 2020 tentang Pedoman Penyelenggaraan Belajar Dalam Masa Darurat Penyebaran Covid-19. 5 dari 7 guru $(71,42 \%)$ menyusun RPP secara luring. Seperti terlihat ada data yang tidak signifikan, hal ini disebabkan karena salah seorang guru memiliki 2 jenis RPP sekaligus yakni RPP daring dan RPP luring. Ditemukan juga guru yang masih menggunakan RPP tahun sebelumnya dengan jenis luring dalam kegiatannya melakukan pembelajaran. Dapat ditarik pernyataan sesuai kekhususan yang berlaku bahwa masih sebagian kecil guru yang mengikuti arahan Kementerian Pendidikan dan Kebudayaan untuk melakukan pembelajaran daring dan penggunaan perangkat RPP daring terkait pandemi covid-19 dengan kategori tidak baik. Namun, penyusunan secara pembelajaran biasa apabila pandemi diabaikan, sebagian besar guru masuk ke dalam kategori baik.

LKPD merupakah jenis handout yang dimaksudkan untuk membantu siswa belajar lebih terarah (guided activities learning). seluruh guru (100\%) menyatakan merancang LKPD dan menyusun indikator hasil belajar terhadap tugas-tugas siswa dengan demikian perancangan LKPD dalam kategori sangat baik. 2 dari 7 guru $(28,57 \%)$ menggunakan LKPD berdasarkan RPP. Masih banyak guru yang menggunakan LKPD berlandaskan pada RPP. Hal ini dikaitkan dengan hasil wawancara bahwa RPP yang dibuat terkadang tidak terimplementasi secara sistematis sehingga beberapa guru ada yang meninggalkan tugas dan tidak memberikan LKPD kepada anak. Sebagian guru juga berpendapat tidak memiliki waktu untuk membuat LKPD sehingga langsung diintegrasikan dengan soal yang ada di buku pegangan siswa. penggunaan LKPD berdasarkan RPP masih dalam kategori tidak baik. 6 Sebanyak 6 guru $(85,71 \%)$ menyatakan mereka 
menggunakan LKPD setiap semesternya. Tidak berarti mereka menggunakan LKPD setiap saat pembelajaran tetapi tetap ada digunakan dalam setiap semester. Berdasarkan hasil wawancara dengan beberapa guru, mereka menyatakan bahwa setiap semester pasti ada menggunakan LKPD seminimal mungkin 1 kali dalam 1 semester. Penggunaan LKPD setiap semester dapat dikategorikan sebagai sangat baik karena sebagian besar guru tetap menggunakan LKPD untuk menambah pemahaman siswa. Dapat dikategorikan bahwa LKPD benar mendukung pencapaian tujuan pembelajaran dengan kategori sangat baik.

Sebanyak 6 dari 7 guru $(85,71 \%)$ menggunakan media pembelajaran. Sedangkan lainnya hanya menggunakannya ketika sedang ingin dipakai saja. Berdasarkan hasil wawancara dengan seluruh guru, terungkap bahwa seluruh guru menggunakan media berupa proyektor ketika melakukan pembelajaran secara luring. 6 guru menyebutkan bahwa mereka menggunakan platform aplikasi untuk melakukan pembelajaran daring. 7 guru menyebut mereka menggunakan media Whatsapp Grup. Hal ini dikarenakan mereka meyakini hanya aplikasi tersebut yang dapat digunakan dan mudah dipahami serta lebih efektif. Selain whatsapp grup, sebagian besar guru mengatakan mereka menggunakan platform Zoom meeting dan Google Classroom untuk melaksanakan tatap muka secara virtual dan memberikan ujian ketika memasuki pembelajaran daring. seluruh guru $(100 \%)$ guru menyatakan bahwa ketika mereka menggunakan media pembelajaran dalam kegiatan belajar mengajar, didapat bahwa terjadi peningkatan hasil belajar terhadap peserta didik. Berdasarkan hasil wawancara lebih lanjut, guru terus terang menyebutkan mereka menggunakan platform yang telah disebutkan diatas untuk mengirimkan tugas, materi tambahan bahkan ujian. Biasanya mereka akan mengirimkan video pembelajaran dan materi yang di dapat dari internet kemudian di share kepada siswa. Sebagian besar video yang di sebarkan merupakan video materi yang diambil dari internet dan sebagian kecil lainnya melakukan pengembangan pada video atau materi yang telah ada. Berdasarkan penjelasan diatas dapat ditarik kesimpulan bahwa penggunaan tersebut dalam kategori penilaian sangat baik.

Seluruh guru (100\%) menyusun materi ajar sendiri. Hasil wawancara didapati bahwa mereka menyusun materi ajar sendiri dengan cara mereka menuliskan dan merangkum materi ajar mereka sendiri. Seluruh guru juga menggunakan buku ajar dari penerbitpenerbit tertentu. Mereka mengaku bahwa 
tidak hanya menggunakan 1 buku dari sekolah saja tetapi juga menggunakan buku lain dengan materi yang sama. Sebagian besar guru mengaku kurang maksimal memberikan materi apabila hanya dengan 1 buku. hanya 4 guru $(42,85 \%)$ yang mengikuti indikator buku ajar dan 6 guru $(85,71 \%)$ guru yang sering menggunakan materi ajar tambahan dari sumber lain. Berdasarkan hasil wawancara ditemukan bahwa indikator pada buku ajar beberapa ada yang tidak linier dengan perangkat pembelajaran lain seperti RPP yang telah dibuat sehingga indikator pada buku ajar tidak diikuti secara penuh. Sedangkan dalam penambahan materi ajar dari sumber lain, seluruh guru menyatakan cara yang paling mudah bagi mereka adalah dengan menemukan sumber materi tambahan dari internet sehingga lebih cepat dan lebih efisien.

Sebanyak 6 guru $(85,71 \%)$ guru menentukan bentuk dan prosedur penilaian sedangkan seorang guru tidak menentukan prosedur penilaian. Berdasarkan hasil wawancara, guru tersebut merahasiakan bentuk penilaian kepada peserta didiknya dengan alasan agar peserta didik tidak bergantung kepada nilai saja melainkan mereka harus bisa mengoreksi diri ketika menjawab soal apakah sudah mampu atau masih belum mampu agar belajar lebih lagi. Berdasarkan gambar 4.6, terungkap bahwa 4 orang guru $(57,14 \%)$ menyusun rencana remedial dan 2 guru $(28,57 \%)$ tidak menyusun rencana remedial. Berdasarkan penjabaran diatas dapat disimpulkan bahwa seluruh guru membuat alat penilaian dan menentukan bentuk penilaian yang berguna untuk mendeskripsikan hasil belajar anak. Remedial tetap dijalankan oleh sebagian guru namun ada beberapa guru yang mengambil penilaian remedial melalui rubrik penilaian lainnya. Jika dibandingkan dengan kategori penilaian, penggunaan tes hasil belajar masuk dalam kategori sangat baik.

\section{KESIMPULAN}

Penggunaan perangkat pembelajaran guru biologi di SMA Negeri 1 Langsa pada masa pandemi Covid-19 dijabarkan dengan pengggunaan RPP sebanyak $87,75 \%$ dengan kategori penilaian sangat baik, LKPD sebanyak $82,85 \%$ dengan kategori penilaian sangat baik, media pembelajaran sebanyak $71,42 \%$ dengan kategori penilaian baik, buku atau materi ajar sebanyak 78,56\% dengan kategori penilaian baik dan tes hasil belajar sebanyak $80,95 \%$ dengan kategori penilaian sangat baik.

\section{DAFTAR PUSTAKA}

Andini, Y. T., \& Widayanti, M. D. (2020). Pelaksanaan Pembelajaran Daring Pada Masa Pandemi Covid-19 di 
TK Bias Yogyakarta. Tarbiyatuna: Kajian Pendidikan Islam, 4(2), 207-216.

Fata, Z., Murtono, S. (2021). Pola Pembelajaran Guru Pada Masa Pandemi Corona (Covid-19) SD Negeri Kramat 3 Kecamatan Dempet Kabupaten Demak. Jurnal Profetika, 22(1), 109-118

Kementerian Pendidikan dan Kebudayaan. (2016). Permendikbud Nomor 22 Tahun 2016 tentang Standar Proses Pendidikan Dasar dan Menengah. Jakarta: Kemendikbud.

Kementerian Pendidikan dan Kebudayaan. (2019). Surat Edaran Mendikbud Nomor 14 Tahun 2019 tentang Penyederhanaan Rencana Pelaksanaan Pembelajaran. Jakarta: Kemendikbud.

Nugroho, N. B. (2014). Pengembangan RPP dan LKS Berbasis Problem Based Learning Pada Materi Himpunan Untuk Siswa Kelas VII. Yogyakarta: Fakultas Matematika dan Ilmu Pengetahuan Alam Universitas Negeri Yogyakarta.

Nursamsu, Baihaqi. (2016). Implementasi Kurikulum 2013 Bagi Guru SMA Negeri Aceh Tamiang. Jurnal Pendidikan Biologi, 5(3), 193-199.

Suciati, R., Astuti, Y. (2016). Analisis Rencana Pelaksanaan Pembelajaran (RPP) Mahasiswa Calon Guru Biologi. Jurnal Edusains, 8(2), 192-200.

Sulistyo, E., \& Setyawati. (2013). Pengembangan Perangkat Pembelajaran Aktif Strategi Giving Question and Getting Answer Terhadap Hasil Belajar Siswa Kelas XI TAV Pada Standar Kompetensi Membuat Rekaman Audio di Studio di SMK Negeri 3 Surabaya. Jurnal Penelitian Pendidikan Elektro, 2(1), 185-193.
Sarjani, Tri Mustika., Marjanah., Pane, Septi Dwi Sapta Rina. (2017). Penggunaan Media Pembelajaran Oleh Guru Biologi di SMA Negeri Se-Kota Langsa Tahun Pelajaran 2016/2017. Jurnal Jeumpa, 4(2), 13-20.

Sasanti, M., Hartini, S., Mahardika, A.I. (2017). Pengembangan LKS Dengan Model Inquiry Discovery Learning (IDL) Untuk Melatihkan Keterampilan Proses Sains Pada Pokok Bahasan Listrik Dinamis. Jurnap Berkala Ilmiah Pendidikan Fisika, 5(1), 46-59.

Suciati, R., Astuti, Y. (2016). Analisis Rencana Pelaksanaan Pembelajaran (RPP) Mahasiswa Calon Guru Biologi. Jurnal Edusains, 8(2), 192-200.

Sugiyono. (2018). Metode Penelitian Kuantitatif, Kualitatif dan $R \& D$. Bandung: Alfabeta.

Sulistyo, E., \& Setyawati. (2013). Pengembangan Perangkat Pembelajaran Aktif Strategi Giving Question and Getting Answer Terhadap Hasil Belajar Siswa Kelas XI TAV Pada Standar Kompetensi Membuat Rekaman Audio di Studio di SMK Negeri 3 Surabaya. Jurnal Penelitian Pendidikan Elektro, 2(1), 185-193.

Sumadi, S. (2014). Metodelogi Penelitian. Jakarta: Grafindo Persada.

Susanto, P. (2010). Buku Petunjuk Teknis Praktik Pengalaman Lapangan Bidang Studi Pendidikan Biologi. Malang: Universitas Negeri Malang.

Trianto, \& al-Tabany, I. B. (2015). Mendesain Model Pembelajaran Inovatif, Progresif Dan Kontekstual: Konsep, Landasan dan Implementasinya Pada 
Kurikulum $2013 \quad$ (Kurikulum

Tematik Integratif). Jakarta:

Kencana Prenada Media Group.

Wahyuningtias, R., Sulasmono B.S. (2020). Pentingnya Media Dalam Pembelajaran Guna Meningkatkan Hasil Belajar Di Sekolah Dasar. Jurnal Basicedu, 2(1), 23-27.

Wati, R. I., Yuliani, \& Isnawati. (2015). Analisis Kesesuaian RPP Materi Fungi di SMA Kabupaten Gresik Dengan Kurikulum 2013. BioEdu Berkala Ilmu Biologi, 4(2), 902907.

Zuhairi. (2016). Pedoman Penulisan Karya Ilmiah. Jakarta: Rajawali Press. 